\title{
Depression augments activity-related pain in women but not in men with chronic musculoskeletal conditions
}

\author{
Heather Adams BSW ${ }^{1}$, Pascal Thibault $\mathrm{MA}^{2}$, Nicole Davidson $\mathrm{BSc}^{3}$, Maureen Simmonds $\mathrm{PhD}^{3}$, \\ Ana Velly $\mathrm{PhD}^{3}$, Michael JL Sullivan $\mathrm{PhD}^{3}$
}

\begin{abstract}
H Adams, P Thibault, N Davidson, M Simmonds, A Velly, MJL Sullivan. Depression augments activity-related pain in women but not in men with chronic musculoskeletal conditions. Pain Res Manage 2008;13(3):236-242.
\end{abstract}

OBJECTIVES: The primary objective of the present study was to examine the role of sex as a moderator of the relation between depression and activity-related pain.

METHODS: The study sample consisted of 83 participants (42 women, 41 men) with musculoskeletal conditions. Participants were asked to lift a series of 18 canisters that varied in weight $(2.9 \mathrm{~kg}$, $3.4 \mathrm{~kg}$ and $3.9 \mathrm{~kg}$ ) and distance from the body. Participants were asked to rate their pain while they lifted each canister and estimate the weight of the canisters.

RESULTS: Consistent with previous research, the relations among depression, pain intensity and disability were stronger for women than for men. ANOVA revealed that depression was associated with more intense activity-related pain in women only. For both women and men, the intensity of pain increased with each trial, although the weight of the objects lifted remained constant. Neither sex nor depression had an effect on participants' weight estimates.

CONCLUSIONS: The present discussion addresses the mechanisms through which depression may differentially affect pain in women and men. It also addresses the potential clinical implications of pain-augmenting effects of depression in women.

Key Words: Depression; Muscle pain; Musculoskeletal pain; Sex differences

Surveys indicate that approximately $20 \%$ to $50 \%$ of indi$\checkmark$ viduals with musculoskeletal conditions show evidence of elevated depressive symptoms (1-4). Recent studies suggest that depressive symptoms associated with musculoskeletal disorders may increase the risk for prolonged work disability (5-8). Individuals with pain-related musculoskeletal conditions and elevated depressive symptoms have a sick leave duration twice as long as individuals with musculoskeletal conditions who do not have depressive symptoms $(9,10)$. Depressive symptoms in individuals with musculoskeletal conditions have also been associated with longer duration of wage replacement benefits following work injury or surgical intervention $(11,12)$.

Nevertheless, not all studies found a relation between depression and recovery outcomes. For example, in a study examining the outcome of rehabilitation treatment in pain patients, Gatchel et al (13) reported no relation between
La dépression augmente la douleur reliée à l'activité chez les femmes mais pas chez les hommes atteints de troubles musculosquelettiques chroniques

OBJECTIFS : L'objectif primaire de la présente étude consistait à examiner le rôle du sexe comme modérateur du lien entre la dépression et la douleur reliée à l'activité.

MÉTHODOLOGIE : L'échantillon de l'étude se composait de 83 parti cipants (42 femmes, 41 hommes) atteints de troubles musculosquelettiques. Les participants ont été invités à soulever une série de 18 bouteilles de poids variable $(2,9 \mathrm{~kg}, 3,4 \mathrm{~kg}$ et $3,9 \mathrm{~kg})$, à distance variable du corps. Les participants devaient ensuite évaluer leur douleur pendant qu'ils soulevaient chacune des bouteilles et estimer le poids de chacune des bouteilles.

RÉSULTATS : Conformément aux recherches antérieures, le lien entre la dépression, l'intensité de la douleur et l'invalidité est plus marqué chez les femmes que chez les hommes. Les analyses de variance révélaient que la dépression s'associait à une douleur plus intense reliée à l'activité chez les femmes seulement. Tant chez les hommes que chez les femmes, l'intensité de la douleur augmentait à chaque essai, même si le poids des objets soulevés demeurait constant. Ni le sexe ni la dépression n'avait d'effet sur l'estimation du poids par les participants.

CONCLUSIONS : Le présent exposé porte sur les mécanismes par lesquels la dépression peut influer sur la douleur de manière différentielle chez les femmes et chez les hommes. Il traite aussi des conséquences cli niques potentielles des effets de la dépression sur l'augmentation de la douleur chez les femmes.

depressive symptoms and rehabilitation outcomes. Schultz et al (14) reported that levels of depression in recently injured workers were not significant predictors of follow-up return-to-work status. At the time of writing, there have been few efforts to explore the factors that determine when depression will be a significant determinant of pain and disability outcomes.

There is a large body of literature indicating that women are more likely to show elevated symptoms of depression $(15,16)$. Women are not only at greater risk for developing depression, they are also at greater risk for relapse following treatment (17). Numerous investigations have also shown that the prevalence of pain-related musculoskeletal conditions is higher in women (18-21). Research suggests that women are at a higher risk for prolonged disability following the onset of a musculoskeletal condition (18-21). These data suggest that the burden of disability associated with pain and depression may be greater for women.

${ }^{1}$ McGill University Health Centre; ${ }^{2}$ Université du Québec à Montréal; ${ }^{3}$ McGill University, Montreal, Quebec

Correspondence and reprints: Dr Michael Sullivan, Department of Psychology, McGill University, 1205 Docteur Penfield Avenue, Montreal,

Quebec H3A 1B1. Telephone 514-398-5677, fax 514-398-4896, e-mail Michael.sullivan@mcgill.ca 
There are indications that sex may be an important moderator of the relationship between depression and disability (22). In a recent study of chronic pain patients, Keogh et al (23) found that depression was associated with increased disability in women, but not in men. Based on their findings, the authors suggested that depression may leave women more vulnerable to disability. Keogh et al (24) also suggested that their findings may explain why women are at greater risk for the development of pain-related problems.

Albeit intriguing, the findings of Keogh et al (24) do not point to the processes that would link depression and disability in women, but not in men. The absence of information about the processes that differentially link depression and disability in women and men compromises efforts to develop rehabilitation interventions specifically targeting the determinants of disability in women and men. Indeed, there are indications that treatment gains following multidisciplinary pain programs are less likely to be maintained by women than by men (23).

The primary objective of the present study was to explore the processes that may differentially link depression and disability in women and men. One of the processes by which depression may affect pain-related disability is by accentuating the negative impact of the activity-related pain symptoms (25). Because disability is typically construed as a reduction in activity participation, measures of activity-related pain, instead of spontaneous or condition-related pain, may be the most relevant pain variables to assess. To our knowledge, the relations among sex, depression and activity-related pain have not been previously studied.

In the present study, women and men with chronic musculoskeletal conditions were asked to lift a series of canisters that varied according to weight and distance from the body. Participants were asked to rate their pain while they lifted each canister and to estimate the weight of the canisters they lifted. In this manner, it was possible to examine whether sex differences in the relation between depression and disability could be accounted for by differences in the perceived effort associated with the lifting task. Secondary analyses were conducted to assess whether pain ratings and weight estimates changed over repeated trials, and whether these changes varied as a function of sex.

\section{METHODS}

\section{Participants}

The study sample consisted of 83 participants (42 women, 41 men) with musculoskeletal conditions. All participants were referred for assessment at one of three pain treatment centres in Montreal, Quebec. At the time of the assessment, all participants were work-disabled due to their musculoskeletal condition and were receiving compensation. The mean age of the sample was 40.8 years, with a range of 20 to 58 years. The mean $( \pm \mathrm{SD})$ number of years spent in pain was $6.8 \pm 6.6$ years. All participants underwent a medical evaluation to ensure there were no medical contraindications to performing the physical manoeuvres involved in the lifting task.

\section{Measures}

Depression: The Beck Depression Inventory II (BDI-II) (26) was used to measure severity of depressive symptoms. The BDI-II consists of 21 items describing various symptoms of depression. Respondents are asked to endorse phrases that best describe how they felt during the past two weeks. The BDI-II has been shown to be a reliable and valid index of depressive symptoms in chronic pain patients $(5,27,28)$.

Participants were classified as 'high' or 'low' depression based on their BDI-II scores. Participants who scored nine or less on the BDI-II were assigned to the low depression group; participants who scored 16 or greater on the BDI-II were assigned to the high depression group. Participants with BDI-II scores between 10 and 15, inclusive, were not included in the analyses. Extreme groups were used to maximize the clinical relevance of the findings. Previous research $(29,30)$ has shown that, in individuals with persistent pain conditions, BDI-II scores above 16 are associated with the best sensitivity and specificity values for a clinical diagnosis of depression.

Pain severity: The McGill Pain Questionnaire (MPQ) (31) was used as a measure of spontaneous (ie, condition-related) pain. On this measure, participants are asked to endorse adjectives that best describe their current pain experience. The MPQ Pain Rating Index (MPQ-PRI) was computed as the weighted sum of all adjectives endorsed. The MPQ-PRI has been shown to be a reliable and valid measure of an individual's chronic pain experience (32).

Disability: The Pain Disability Index (PDI) (33) was used as a self-report measure of pain-related disability. On this measure, participants are asked to rate their level of disability in seven different areas of daily living (home, social, recreational, occupational, sexual, self-care, life support). The PDI has been shown to be internally reliable and significantly correlated with objective measures of disability (34).

\section{Procedure and apparatus}

The present study received ethical approval from the Ethics Review Committee of the Université de Montréal and the Centre de recherche interdisciplinaire en réadaptation du Montréal métropolitain. Participants signed a consent form as a condition of participation in the research. Participants were asked to complete the MPQ, the PDI and the BDI-II as part of their initial assessment. Participants were informed that the study aimed to develop a new assessment procedure for individuals suffering from persistent pain. They were made aware that the lifting task may lead to temporary increases in discomfort and they were free to discontinue at any point.

The lifting task was the same as that described by Sullivan et al (35), and consisted of 18 canisters (4 $\mathrm{L}$ paint canisters) partially filled with sand and placed on a table (surface $80 \mathrm{~cm}$ $\times 120 \mathrm{~cm}$ ) adjusted to waist height for each participant. The canisters weighed $2.9 \mathrm{~kg}, 3.4 \mathrm{~kg}$ or $3.9 \mathrm{~kg}$ and were arranged in three rows of six canisters. Within the $3 \times 6$ matrix, each weight was represented twice in each location of a double latin square. The selection of loads was based on research suggesting a $12 \%$ weight difference as a detection threshold, and National Institute for Occupational Safety and Health recommendations for safe weight limits $(36,37)$. The movements required to lift the canisters recruit musculature of the shoulders and lower back, areas of the body likely to be associated with pain in individuals with musculoskeletal conditions.

As shown in Figure 1, the canister locations required the adoption of three different functional anthropometric postural positions: normal, maximum and extreme reaches (38). In the normal reach position (position 1), the participant stands erect with his or her elbow bent at $90^{\circ}$; in the maximum reach position (position 2), the participant stands erect with his or her arm fully extended; in the extreme reach condition, 


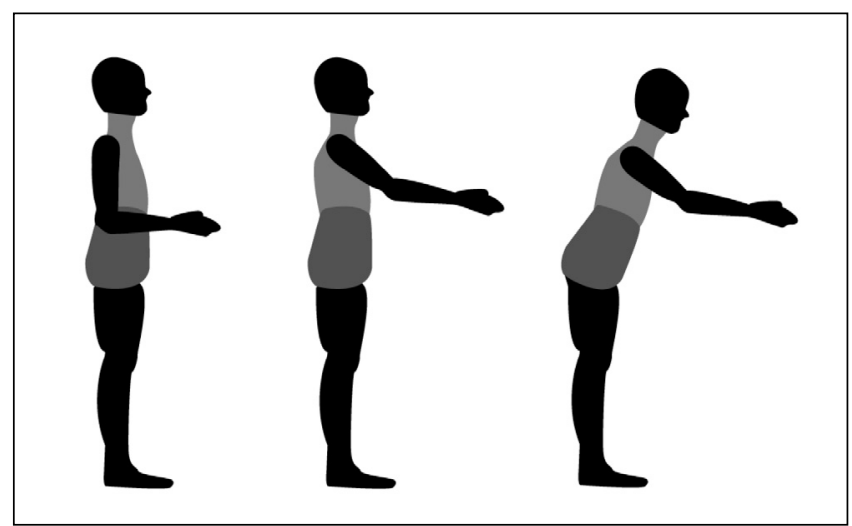

Figure 1) Postural positions required to perform the lifting task

the participant is forward flexed with his or her arm fully extended (38). The participants were asked to perform two different tasks - a pain rating task and a weight estimation task.

Pain rating task: Participants were asked to lift the 18 canisters, with their dominant arm, in a predetermined sequence (ie, column 1, first, second, third position; column 2, first, second, third position; etc). Participants were asked to provide a verbal rating of their pain as they lifted each canister, on an 11-point scale with the end points 0 (no pain) and 10 (extreme pain).

Weight estimation task: Participants lifted the same canisters, with their dominant arm, in the same sequence as they were lifted in the pain rating task. Participants were asked to estimate the weight of each canister and to provide a verbal estimate in imperial or metric units. All weight estimates were later converted to metric units. For the purposes of the present study, weight estimates were used as a proxy for perceived effort.

\section{Data reduction}

As described above, the lifting task required participants to lift 18 canisters arranged in six columns of three canisters. Each weight was represented in each column, thus equalizing columns in terms of the total weight lifted. For the purposes of the present study, the average pain rating or weight estimate within each column was used as the unit of analysis.

The pain rating and weight estimation data from the lifting task were analyzed as a three-way mixed factorial with sex (women, men) and level of depression (high, low) as betweengroups factors, and trial (columns 1 to 6) as the within-groups factor.

\section{Sample characteristics}

\section{RESULTS}

Means and SDs for sample demographics and pain condition characteristics are presented in Table 1. Scores on measures of pain severity and self-reported disability are comparable with those that were reported in previous research on pain behaviour in chronic pain patients $(39,40)$. Women and men did not differ significantly in age, $t(81)=1.0$, not significant $(\mathrm{ns})$, or pain duration, $t(81)=0.37$, ns. A higher proportion of women had completed high school than men, $\chi^{2}=2.4, \quad \mathrm{P}<0.05$. Compared with men, women obtained higher scores on the MPQ-PRI, $t(81)=2.6, \mathrm{P}<0.01$, on the PDI, $t(81)=2.7, \mathrm{P}<0.01$ and on the BDI-II, $t(81)=2.9, \mathrm{P}<0.01$.
TABLE 1

Sample characteristics

\begin{tabular}{lccl}
\hline & $\begin{array}{c}\text { Women } \\
(\mathbf{n = 4 2})\end{array}$ & $\begin{array}{c}\text { Men } \\
(\mathbf{n = 4 1 )}\end{array}$ & $\mathbf{P}$ \\
\hline Age & $41.8 \pm 10.7$ & $39.7 \pm 8.5$ & $\mathrm{~ns}$ \\
Injury site & $70 \%$ back & $75 \%$ back & $\mathrm{ns}$ \\
Education & $90 \%$ high school & $70 \%$ high school & 0.05 \\
Pain duration & $7.2 \pm 7.0$ & $6.5 \pm 6.0$ & $\mathrm{~ns}$ \\
MPQ-PRI & $34.5 \pm 18.1$ & $25.1 \pm 13.0$ & $<0.01$ \\
BDI-II & $21.8 \pm 14.1$ & $13.3 \pm 10.3$ & 0.01 \\
PDI & $35.1 \pm 18.9$ & $25.2 \pm 14.3$ & 0.01
\end{tabular}

Age and pain duration measured in years. Results presented as mean $\pm S D$ unless stated otherwise. BDI-II Beck Depression Inventory II; MPQ-PRI McGill Pain Questionnaire Pain Rating Index; ns Not significant; PDI Pain Disability Index

TABLE 2

Correlations ( $r$ ) among dependent measures for women and men

\begin{tabular}{lllll}
\hline & $\mathbf{1}$ & $\mathbf{2}$ & $\mathbf{3}$ & $\mathbf{4}$ \\
\hline 1. MPQ-PRI & - & $0.45^{\star \star}$ & $0.43^{\star \star}$ & $0.50^{\star \star}$ \\
2. BDI-II & 0.26 & - & $0.58^{\star *}$ & $0.39^{\star \star}$ \\
3. PDI & $0.44^{\star *}$ & $0.41^{\star *}$ & - & $0.52^{\star \star}$ \\
4. Pain lift & $0.34^{\star}$ & 0.03 & $0.31^{*}$ & - \\
\hline
\end{tabular}

Correlations above the diagonal are for women; correlations below the diagonal are for men. Pain lift is the average pain rating (0 to 10) provided across 18 canister lifts. ${ }^{*} P<0.05 ;{ }^{*} P<0.01$. BDI-II Beck Depression Inventory II; MPQ-PRI McGill Pain Questionnaire Pain Rating Index; PDI Pain Disability Index

In the low depression group, there were 15 women and 25 men; in the high depression group, there were 27 women and 16 men, $\chi^{2}=5.3, P<0.05$. In the low depression group, there were no significant sex differences in mean BDI-II scores (women $5.8 \pm 3.2$, men $5.4 \pm 3.0, t(38)=0.37$, ns). In the high depression group, women obtained significantly higher mean BDI-II scores $(30.4 \pm 9.3)$ than men $(24.0 \pm 6.4), t(41)=2.4$, $\mathrm{P}=0.02$.

Correlations among dependent measures

Correlations among measures of pain, depression and selfreported disability were computed separately for women and men. In Table 2, correlations computed for women are displayed above the diagonal and correlations for men are displayed below the diagonal. The results partially replicate previous research on the relations among pain, depression and disability. The correlation between depression and selfreported disability was slightly (but not significantly) higher for women $(r=0.58, \mathrm{P}<0.01)$ than for men $(r=0.41, \mathrm{P}<0.01)$. Depression was significantly correlated with pain ratings (MPQ-PRI and activity-related pain) for women but not for men. Sex differences in the magnitude of correlations between depression and pain were significant for pain ratings made during the lifting task, $z=1.7, \mathrm{P}<0.05$, but not for MPQ-PRI scores.

Measures of spontaneous pain (MPQ-PRI) and activityrelated pain were differentially associated with self-reported disability in women and in men. When both pain measures were included in a direct regression analysis, activity-related pain $(\beta=0.40, P<0.01)$, but not the MPQ-PRI $(\beta=0.23$, ns), contributed significant unique variance to the prediction of 
TABLE 3

Pain ratings during canister lifts as a function of sex and trial

\begin{tabular}{lcc}
\hline Trial & Women & Men \\
\hline 1 & $4.8 \pm 2.4$ & $2.6 \pm 2.1$ \\
2 & $5.1 \pm 2.6$ & $2.9 \pm 2.4$ \\
3 & $5.5 \pm 2.6$ & $3.4 \pm 2.3$ \\
4 & $5.3 \pm 2.6$ & $3.3 \pm 2.4$ \\
5 & $5.3 \pm 2.6$ & $3.4 \pm 2.4$ \\
6 & $5.7 \pm 2.7$ & $3.6 \pm 2.5$ \\
\hline
\end{tabular}

Results are presented as mean $\pm S D$. Trial 1 is the average pain rating provided for the three canisters in column 1, Trial 2 is the average pain rating for the three canisters in column 2, etc

self-reported disability. For men, the MPQ-PRI $(\beta=0.38$, $\mathrm{P}<0.01)$, but not activity-related pain $(\beta=0.18$, ns), contributed significant unique variance to the prediction of self-reported disability.

\section{Activity-related pain ratings}

A three-way sex $\times$ level of depression $\times$ trials ANOVA was conducted on activity-related pain ratings. The analysis yielded significant main effects for sex, $\mathrm{F}(1,79)=11.4, \mathrm{P}<0.001$, and trials, $\mathrm{F}(5,395)=14.9, \mathrm{P}<0.001$. The main effect for level of depression failed to reach statistical significance, $\mathrm{F}(1,79)=2.8, \mathrm{P}=0.08$. A significant sex $\times$ level of depression interaction was obtained, $\mathrm{F}(1,79)=4.3, \mathrm{P}<0.05$, indicating that level of depression moderated the relation between sex and activity-related pain. Mean and standard deviations for the main effect of sex on activity-related pain ratings are presented in Table 3. Across all trials, women rated their activity-related pain as more severe than men. For both men and women, there was a significant linear trend reflecting increasing pain over repeated trials, $\mathrm{F}(1,79)=25.4, \mathrm{P}<0.001$. Figure 2 displays the mean activity-related pain ratings for women and men separately, as a function of level of depression and trials. Depression contributed to a significant increase in activity-related pain ratings for women, but not for men.

Given that women and men in the high depression group differed with respect to their scores on the BDI-II, it is possible that sex-dependent differences in the relation between depression and activity-related pain may be the result of women's more extreme depression scores. A hierarchical regression was conducted to examine whether the sex $\times$ level of depression interaction remained significant even when controlling for scores on the BDI-II. In this analysis, mean activity-related pain was used as the dependent variable. Sex and level of depression were entered in the first step of the analysis and contributed significantly to the prediction of pain, $\mathrm{R}^{2}=0.21, \mathrm{~F}(2,80)=9.4, \mathrm{P}<0.001$. BDI-II scores were entered in the second step of the analysis but did not contribute significantly to the prediction of pain ratings beyond the variance accounted for by sex and level of depression, $\mathrm{R}_{\text {change }}=0.02, \mathrm{~F}(1,79)=1.8, \mathrm{P}=0.16$. The sex $\times$ level of depression interaction was entered in the third step of the analysis and contributed significantly to the prediction of pain ratings, $\mathrm{R}_{\text {change }}^{2}=\mathrm{F}(1,78)=3.5, \mathrm{P}<0.05$. The results of this analysis indicate that women's more extreme scores on the BDI-II do not account for the sex-dependent relation between depression and activity-related pain.

An analysis of covariance was conducted to address whether sex differences in activity-related pain were simply a

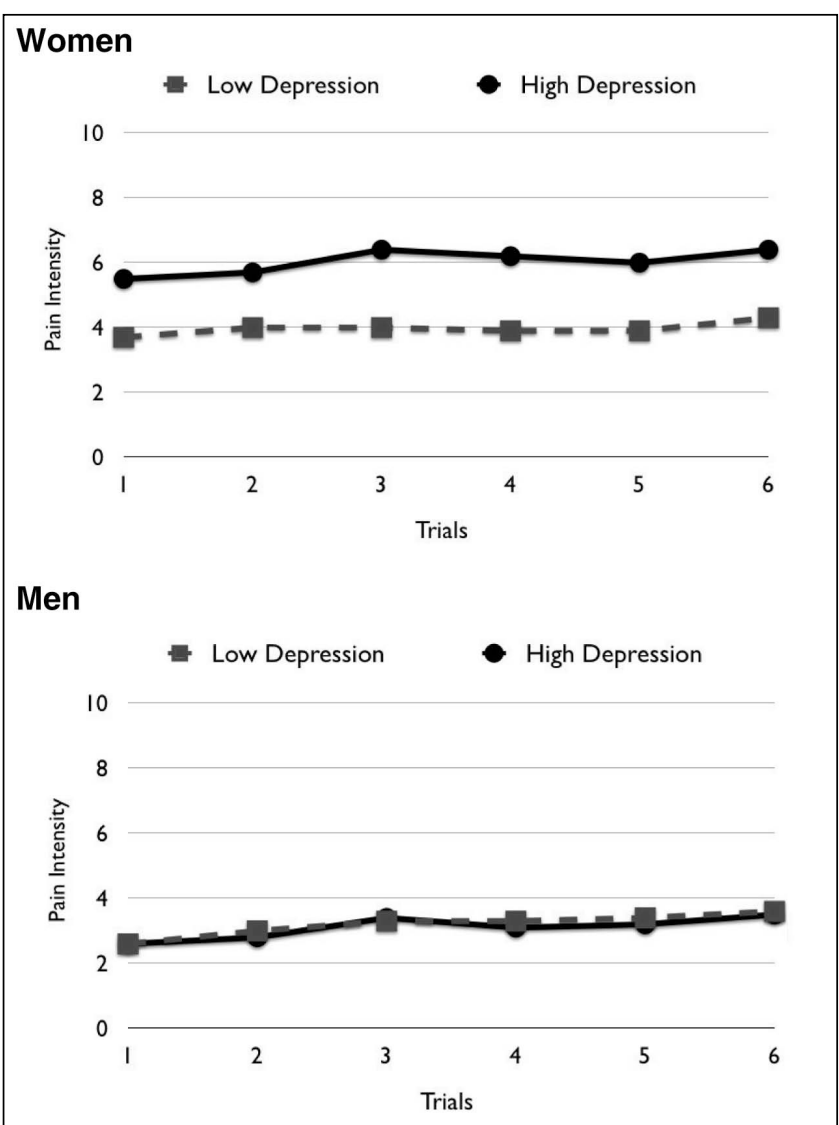

Figure 2) Activity-related pain ratings as a function of level of depression and trials

reflection of more severe spontaneous (ie, condition-related) pain. In this analysis, the main effect of sex on activity-related pain was examined using the MPQ-PRI as a covariate. The results of this analysis indicated that the main effect of sex on activity-related pain remained significant even when MPQPRI scores were statistically controlled, $\mathrm{F}(1,80)=8.3, \mathrm{P}<0.01$.

\section{Weight estimates}

As noted earlier, weight estimates were used as a proxy for perceived effort. A three-way (sex $\times$ level of depression $\times$ trials) mixed ANOVA was conducted on participants' weight estimates of the canisters they lifted. The analysis yielded only a main effect for trials, $F(5,395)=21.9, P<0.001$. As shown in Table 4, there was a significant linear trend reflecting increasing weight estimates over trials, $\mathrm{F}(1,79)=32.9, \mathrm{P}<0.001$. The main effects for sex, $F(1,79)=1.0$, ns, and level of depression, $\mathrm{F}(1,79)=0.06$, ns, did not approach statistical significance. The absence of significant effects for sex and level of depression on weight estimates indicates that variations in perceived effort do not account for the sex-dependent relations between depression and activity-related pain.

\section{DISCUSSION}

The findings of the present research join a growing body of literature showing that women experience more severe pain than men $(18,20)$. In the present study, sex differences in pain experience were found not only for spontaneous pain (ie, using the MPQ-PRI) but for activity-related pain as well. In addition, sex 
TABLE 4

Weight estimates (in $\mathbf{k g}$ ) as a function of sex and trial

\begin{tabular}{lcc}
\hline Trial & Women & Men \\
\hline 1 & $3.1 \pm 2.9$ & $2.4 \pm 1.5$ \\
2 & $3.6 \pm 3.4$ & $3.0 \pm 2.2$ \\
3 & $4.3 \pm 4.0$ & $3.4 \pm 2.3$ \\
4 & $3.9 \pm 4.6$ & $3.0 \pm 1.8$ \\
5 & $4.0 \pm 3.9$ & $3.4 \pm 2.4$ \\
6 & $4.2 \pm 4.4$ & $3.6 \pm 2.5$ \\
\hline
\end{tabular}

Results are presented as mean $\pm S D$. Trial 1 is the average weight estimate provided for the three canisters in column 1, Trial 2 is the weight estimate for the three canisters in column 2, etc

differences in activity-related pain remained significant even when controlling for MPQ-PRI scores. The latter finding suggests that activity-related pain is a dimension of pain experience not captured by self-report measures of spontaneous or condition-related pain.

The results of correlational analyses on self-report measures of pain, depression and disability were partially consistent with those reported in previous research. Bolton (22) and Keogh et al (24) reported that depression was correlated with self-reported disability in women but not in men. In the present study, depression was correlated with self-reported disability for both men and women; however, the correlation was slightly higher in women than in men. Consistent with Keogh et al (24), the present study did show that depression was correlated with pain ratings (activity-related pain) for women, but not for men.

A few studies (41-43) have reported that the relation between depression and pain is greater in men than in women, and some studies have reported no sex differences in the relation between depression and pain (44). An explanation for these discrepant findings is not readily apparent. Two of the studies that have reported stronger depression-pain relations in men have been conducted with older adults $(41,42)$. It is possible that life stage-related changes in the prevalence of depression, or sex-specific changes in hormonal mechanisms implicated in depression, may account for differences in depression-pain relations in older adults (45-47). More research is needed to clarify the sample characteristics that will determine the nature of sex differences in relations between depression and pain.

The results of the present study extend previous research in showing that depression augments activity-related pain in women, but not in men. In women, high levels of depression, compared with low levels of depression, were associated with approximately $40 \%$ more intense pain while performing the lifting task. Depression had a near-zero impact on activityrelated pain in men. Given that depression occurs more frequently in women, its more negative impact on pain experience in women may help explain why women may be at greater risk for prolonged disability following musculoskeletal injury. If depressive symptoms act to amplify pain symptoms in women, they may be more likely to reach tolerance limits that affect their participation in activity.

In the depressed group, women obtained higher scores on the BDI-II than men. It could, therefore, be argued that the absence of a pain-augmenting effect from depression in men is due to the fact that the depression scores of men were not sufficiently elevated to influence their pain experience. The results do not support such an explanation. Even when controlling for scores on the BDI-II, the interaction between sex and level of depression remained significant. It is also unlikely that the pain-augmenting effect of depression in women was due to sex differences in perceived effort. Analyses revealed no significant effects due to sex or level of depression on participants' weight estimates. It is important to note, however, that weight estimation is an indirect measure of perceived effort (48). More direct measures of perceived effort or fatigue will be required to conclusively rule out the potential role of sex differences in perceptions of effort as an account of the painaugmenting effects of depression in women.

In a previous study using the same lifting paradigm, Sullivan et al (35) reported significant sex differences in activity-related pain ratings and weight estimates. In the present study, women consistently provided higher weight estimates than men; however, unlike Sullivan et al (35), the differences did not attain statistical significance. The results of the present study suggest that the relation between sex and weight estimates is associated with a small effect size and may not be reliably reproducible.

Previous discussions of the relation between sex and disability have appealed to social role explanations. It has been suggested that women may hold beliefs about the relation between depression and pain that impact negatively on their experience (24). It has also been suggested that the multiple role demands of women may require that they establish priorities of involvement. Under conditions of compromised resources, family role responsibilities may be accorded higher priority status than occupational role responsibilities. Although the present findings do not question the tenability of social role explanations of disability in women with musculoskeletal conditions, they suggest that factors at a more basic level may also be playing a role.

Recent studies suggest that the relation between depression and pain sensitivity may vary as a function of the modality of pain stimulation (49). In a sample predominantly composed of women, Bär et al (50) reported that depression was associated with 'hypoalgesic' responses to heat and electrical stimulation, and 'hyperalgesic' responses to muscle ischemic pain. It has been suggested that hypoalgesic responses in depression may be the result of diminished spinal or brainstem transmission, while hyperalgesic responses in depression may be the result of insufficient activation of endogenous opioid pain inhibitory systems (49). Findings showing reduced efficacy of opioids in women further suggest the possibility that central pain inhibitory systems may be activated differently in women and men (51).

Recent research suggests that hormonal factors may underlie observed sex differences in the frequency and mechanisms of pain and depression in women and men (52-54). It has been suggested that hormonal factors may reduce the sensitivity of $\mu$-opioid receptors in women (55). It has been shown that luteinizing hormone desensitizes opioid receptors, leading to decreased effectiveness of endogenous and exogenous opioids (56). It is possible that similar hormonal processes may contribute to the differential impact of depression on activityrelated pain in women and men.

Women's greater tendency to ruminate, or to become internally or emotionally focused when depressed, may also explain why depression may affect women's pain experiences in a manner different from that of men (57-60). If women are more likely than men to become internally focused when 
depressed, the increased attention to pain symptoms may inadvertently lead to a more severe pain experience. It has also been shown that depression potentiates an information processing bias for pain-related stimuli. Although the question has not been investigated, it is possible that such a processing bias is more pronounced in women than in men (61).

Unfortunately, the results of the present study do not permit favouring one of the above potential explanations of the sex-dependent relation between depression and activityrelated pain. Future research examining attentional or copingrelated processes may elucidate underlying mechanisms. Research incorporating assessment of descending modulatory mechanisms, such as the nociceptive flexion reflex, may also reveal a basis for the differential impact of depression on activity-related pain in women and men (62).

From a clinical perspective, the present findings point to the importance of effectively treating depression in women with persistent pain. In the past, some authors have suggested using antidepressants as a primary treatment for persistent pain (63). Although research has not supported the use of antidepressants as a primary treatment for persistent pain, there are indications that reductions in depression may be a prerequisite to pain reduction in individuals with concomitant symptoms of pain and depression (64). Unfortunately, depression continues to be underdetected in patients with persistent pain, and pain patients with depressive symptoms are more likely to be prescribed opioids instead of receiving treatment for depression $(64,65)$. Even when antidepressant medication is considered, many pain patients with high levels of depressive symptoms are prescribed antidepressants at doses below the therapeutic range (66). Surprisingly, there have been few clinical trials examining the efficacy of antidepressants in depressed patients with musculoskeletal pain $(4,67)$.

Some caution is warranted in the interpretation of the findings of the present study. First, depression was operationalized as a high score on a self-report measure of depressive symptoms as opposed to a diagnostic interview. To date, the bulk of research on depression associated with musculoskeletal conditions has been conducted with self-report measures (68). High scores on self-report measures of depressive symptoms do not imply that the diagnostic criteria for a depressive disorder have been met. More research is needed to address the prognostic value of diagnoses of depressive conditions verified by structured diagnostic interviews.

Another limitation of the present findings is that pain was induced under laboratory conditions that may not resemble the conditions under which activity-related pain is typically experienced. In the present study, participants were reassured that the lifting task was safe and would not lead to adverse negative health consequences. Under experimental conditions where safety concerns are paramount and the potential negative consequences of participation must be minimized, the laboratory context may differ in important ways from the day-to-day experiences of pain patients, and the degree of generalizability of findings may be compromised to some extent. Finally, the quasi-experimental design, using pre-existing levels of depression, limits the confidence that can be had in conclusions about the causal status of depression on activity-related pain.

In spite of these limitations, the present findings provide preliminary evidence that depression augments activityrelated pain in women, but not in men. These findings may help explain why women experience more pronounced and prolonged pain-related disability than men. The findings may also bring attention to the detection and treatment of depressive symptoms in women with persistent pain conditions.

ACKNOWLEDGEMENTS: The authors thank Danica Layton and Elizabeth McLaughlin for their assistance with data entry. The authors also thank Dr Richard Catchlove for conducting the medical evaluations of patients who participated in this research. This research was supported by grants from the Institut de recherche Robert-Sauvé en santé et en sécurité $d u$ travail and the Canadian Institutes of Health Research.

\section{REFERENCES}

1. Campbell L, Clauw D, Keefe F. Persistent pain and depression: A biopsychosocial perspective. Biol Psychiatry 2003;54:399-409.

2. McWilliams LA, Cox BJ, Enns MW. Mood and anxiety disorders associated with chronic pain: An examination in a nationally representative sample. Pain 2003;106:127-33.

3. Rush AJ, Polatin P, Gatchel RJ. Depression and chronic low back pain: Establishing priorities in treatment. Spine 2000;25:2566-71.

4. Sullivan MJ, Reesor K, Mikail S, Fisher R. The treatment of depression in chronic low back pain: Review and recommendations. Pain 1992;50:5-13

5. Sullivan MJ, Stanish WD. Psychologically based occupational rehabilitation: The Pain-Disability Prevention Program. Clin J Pain 2003;19:97-104.

6. Sullivan MJ, Adams H, Thibault P, Corbière M, Stanish WD. Initial depression severity and the trajectory of recovery following cognitive-behavioral intervention for work disability. J Occup Rehabil 2006;16:63-74.

7. Vowles KE, Gross RT, Sorrell JT. Predicting work status following interdisciplinary treatment for chronic pain. Eur J Pain 2004;8:351-8.

8. Rezai M, Côté P. Which came first - the depression or the pain? $<$ http://www.iwh.on.ca/archive/pdfs/Linkages15.pdf> (Version current at May 22, 2008).

9. Currie S, Wang J. Chronic back pain and major depression in the general Canadian population. Pain 2004;107:54-60.

10. Druss BG, Rosenheck RA, Sledge WH. Health and disability costs of depressive illness in a major US corporation. Am J Psychiatry 2000;157:1274-8.

11. Dozois DJ, Dobson KS, Wong M, Hughes D, Long A. Factors associated with rehabilitation outcome in patients with low back pain (LBP): Prediction of employment outcome at 9-month followup. Rehabil Psychol 1995;40:243-59.

12. Schade V, Semmer N, Main CJ, Hora J, Boos N. The impact of clinical, morphological, psychosocial and work-related factors on the outcome of lumbar discectomy. Pain 1999;80:239-49.

13. Gatchel R, Polatin P, Noe C, Gardea M, Pulliam C, Thompson J. Treatment- and cost-effectiveness of early intervention for acute low-back pain patients: A one-year prospective study. J Occup Rehabil 2003;13:1-9.

14. Schultz IZ, Crook J, Meloche GR, et al. Psychosocial factors predictive of occupational low back disability: Towards development of a return-to-work model. Pain 2004;107:77-85

15. Altemus M. Sex differences in depression and anxiety disorders: Potential biological determinants. Horm Behav 2006;50:534-8.

16. Maciejewski PK, Prigerson HG, Mazure CM. Sex differences in event-related risk for major depression. Psychol Med 2001;31:593-604.

17. Kuehner C. Gender differences in unipolar depression: An update of epidemiological findings and possible explanations. Acta Psychiatr Scand 2003;108:163-74.

18. Fillingim RB. Sex, Gender, and Pain. Seattle: IASP Press, 2000.

19. Waddell G, Burton AK, Main CJ. Screening to Identify People at Risk of Long-Term Incapacity for Work: A Conceptual and Scientific Review. London: Royal Society of Medicine Press; 2003. 
20. Unruh AM. Gender variations in clinical pain experience. Pain 1996;65:123-67.

21. Wijnhoven HA, de Vet HC, Picavet HS. Prevalence of musculoskeletal disorders is systematically higher in women than in men. Clin J Pain 2006;22:717-24.

22. Bolton JE. Psychological distress and disability in back pain patients: Evidence of sex differences. J Psychosom Res 1994;38:849-58.

23. Keogh E, McCracken LM, Eccleston C. Do men and women differ in their response to interdisciplinary chronic pain management? Pain 2005;114:37-46.

24. Keogh E, McCracken LM, Eccleston C. Gender moderates the association between depression and disability in chronic pain patients. Eur J Pain 2006;10:413-22.

25. Berglund A, Bodin L, Jensen I, Wiklund A, Alfredsson L. The influence of prognostic factors on neck pain intensity, disability, anxiety and depression over a 2-year period in subjects with acute whiplash injury. Pain 2006;125:244-56.

26. Beck AT, Steer RA, Brown GK. Manual for the Beck Depression Inventory II. San Antonio: Psychological Corporation, 1996.

27. Vowles KE, Gross RT, Sorrell JT. Predicting work status following interdisciplinary treatment for chronic pain. Eur J Pain 2004;8:351-8.

28. Poole H, Bramwell R, Murphy P. Factor structure of the Beck Depression Inventory-II in patients with chronic pain. Clin J Pain 2006;22:790-8.

29. Harris CA, D'Eon JL. Psychometric properties of the Beck Depression Inventory - Second Edition (BDI-II) in individuals with chronic pain. Pain 2007. (In press)

30. Bishop S, Edgley K, Fisher R, Sullivan M. Screening for depression in chronic low back pain with the Beck Depression Inventory. Can J Rehabil 1993; 7:143-8.

31. Melzack R. The McGill Pain Questionnaire: Major properties and scoring methods. Pain 1975;1:277-99.

32. Turk DC, Rudy TE, Salovey P. The McGill Pain Questionnaire reconsidered: Confirming the factor structure and examining appropriate uses. Pain 1985;21:385-97.

33. Pollard CA. Preliminary validity study of the pain disability index. Percept Mot Skills 1984;59:974.

34. Tait RC, Chibnall JT, Krause S. The Pain Disability Index: Psychometric properties. Pain 1990;40:171-82.

35. Sullivan MJ, Thibault P, Savard A, Catchlove R, Kozey J, Stanish WD. The influence of communication goals and physical demands on different dimensions of pain behavior. Pain 2006;125:270-7.

36. Karwowski W, Shumate C, Yates JW, Pongpatana N. Discriminability of load heaviness: Implications for the psychophysical approach to manual lifting. Ergonomics 1992;35:729-44.

37. Waters T, Putz-Anderson V, Garg A, Fine L. Revised NIOSH equation for the design and evaluation of manual lifting tasks. Ergonomics 1993;36:749-76.

38. Butler HL, Kosey JW. The effect of load and posture on load estimations during a simulated lifting task in female workers. Int J Ind Ergon 2003;31:331-41.

39. McCahon S, Strong J, Sharry R, Cramond T. Self-report and pain behavior among patients with chronic pain. Clin J Pain 2005;21:223-31.

40. Hill ML, Craig KD. Detecting deception in facial expressions of pain: Accuracy and training. Clin J Pain 2004;20:415-22.

41. Geerlings SW, Twisk JW, Beekman AT, Deeg DJ, van Tilburg W. Longitudinal relationship between pain and depression in older adults: Sex, age and physical disability. Soc Psychiatry Psychiatr Epidemiol 2002;37:23-30.

42. Hirsh AT, Waxenberg LB, Atchison JW, Gremillion HA, Robinson ME. Evidence for sex differences in the relationships of pain, mood, and disability. J Pain 2006;7:592-601.

43. Riley JL, Robinson ME, Wade JB, Myers CD, Price DD. Sex differences in negative emotional responses to chronic pain. J Pain 2001;2:354-9.

44. Edwards R, Augustson EM, Fillingim R. Sex-specific effects of painrelated anxiety on adjustment to chronic pain. Clin J Pain 2000; $16: 46-53$
45. Rajewska J, Rybakowski JK. Depression in premenopausal women: Gonadal hormones and serotonergic system assessed by D-fenfluramine challenge test. Prog Neuropsychopharmacol Biol Psychiatry 2003;27:705-9.

46. Studd J, Panay N. Hormones and depression in women. Climacteric 2004;7:338-46

47. Freeman EW, Sammel MD, Lin H, Nelson DB. Associations of hormones and menopausal status with depressed mood in women with no history of depression. Arch Gen Psychiatry 2006;63:375-82.

48. Deeb JM. Muscular fatigue and its effects on weight perception. Int J Ind Ergon 1999;24:223-33.

49. Lautenbacher S, Roscher S, Strian D, Fassbender K, Krumrey K, Krieg JC. Pain perception in depression: Relationships to symptomatology and naloxone-sensitive mechanisms. Psychosom Med 1994;56:345-52.

50. Bär KJ, Brehm S, Boettger MK, Boettger S, Wagner G, Sauer H Pain perception in major depression depends on pain modality. Pain 2005;117:97-103

51. Sarton E, Olofsen E, Romberg R, et al. Sex differences in morphine analgesia: An experimental study in healthy volunteers. Anesthesiology 2000;93:1245-54.

52. LeResche L, Mancl L, Sherman JJ, Gandara B, Dworkin SF. Changes in temporomandibular pain and other symptoms across the menstrual cycle. Pain 2003;106:253-61.

53. Fillingim RB, Ness TJ. Sex-related hormonal influences on pain and analgesic responses. Neurosci Biobehav Rev 2000;24:485-501.

54. Rhudy JL, Williams AE. Gender differences in pain: Do emotions play a role? Gend Med 2005;2:208-26.

55. Zubieta JK, Dannals RF, Frost JJ. Gender and age influences on human brain mu-opioid receptor binding measured by PET. Am J Psychiatry 1999;156:842-8.

56. Berglund LA, Derendorf H, Simpkins JW. Desensitization of brain opiate receptor mechanisms by gonadal steroid treatments that stimulate luteinizing hormone secretion. Endocrinology $1988 ; 122: 2718-26$

57. Nolen-Hoeksema S. Gender differences in depression. Curr Dir Psychol Sci 2001;10:173-6.

58. Piccinelli M, Wilkinson G. Gender differences in depression. Critical review. Br J Psychiatry 2000;177:486-92.

59. Martin RC, Dahlen ER. Cognitive emotion regulation in the prediction of depression, anxiety, stress, and anger. Pers Individ Dif 2005;39:1249-60.

60. Roth RS, Geisser ME, Theisen-Goodvich M, Dixon PJ. Cognitive complaints are associated with depression, fatigue, female sex, and pain catastrophizing in patients with chronic pain. Arch Phys Med Rehabil 2005;86:1147-54.

61. Nikendei C, Dengler W, Wiedemann G, Pauli P. Selective processing of pain-related word stimuli in subclinical depression as indicated by event-related brain potentials. Biol Psychol 2005;70:52-60.

62. Rhudy JL, Maynard LJ, Russell JL. Does in vivo catastrophizing engage descending modulation of spinal nociception? J Pain 2007;8:325-33

63. Blumer D, Heilbronn M. Chronic pain as a variant of depressive disease: The pain-prone disorder. J Nerv Ment Dis 1982;170:381-406

64. Sullivan MJ, Adams H, Tripp D, Stanish WD. Stage of chronicity and treatment response in patients with musculoskeletal injuries and concurrent symptoms of depression. Pain 2008;135:151-9.

65. Doan BD, Wadden NP. Relationships between depressive symptoms and descriptions of chronic pain. Pain 1989;36:75-84.

66. Polatin PB, Dersh J. Psychotropic medication in chronic spinal disorders. Spine J 2004;4:436-50.

67. Sullivan MD, Robinson JP. Antidepressant and anticonvulsant medication for chronic pain. Phys Med Rehabil Clin N Am. 2006;17:381-400,vi-vii.

68. Geisser ME, Roth RS, Robinson ME. Assessing depression among persons with chronic pain using the Center for Epidemiological Studies-Depression Scale and the Beck Depression Inventory: A comparative analysis. Clin J Pain 1997;13:163-70. 


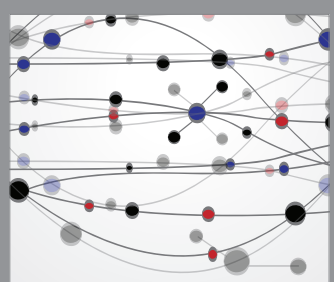

The Scientific World Journal
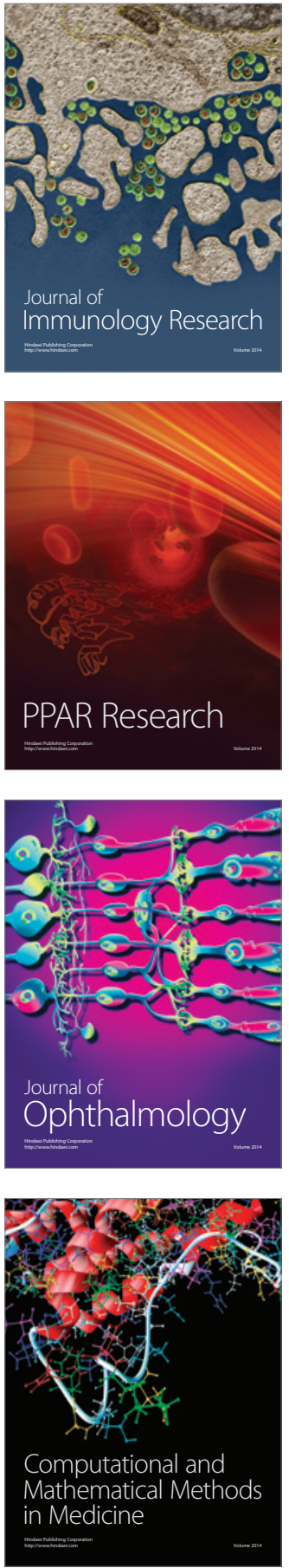

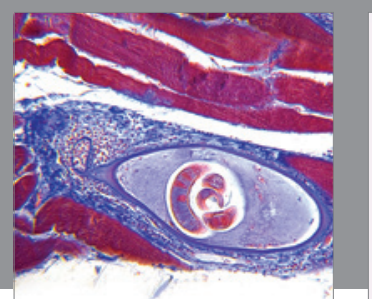

Gastroenterology Research and Practice

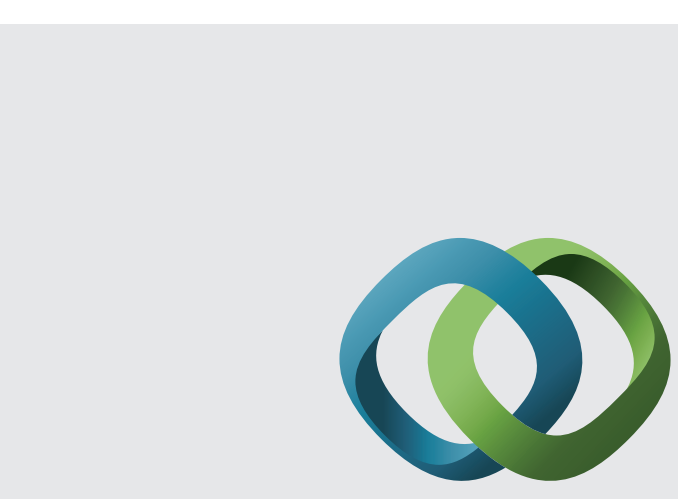

\section{Hindawi}

Submit your manuscripts at

http://www.hindawi.com
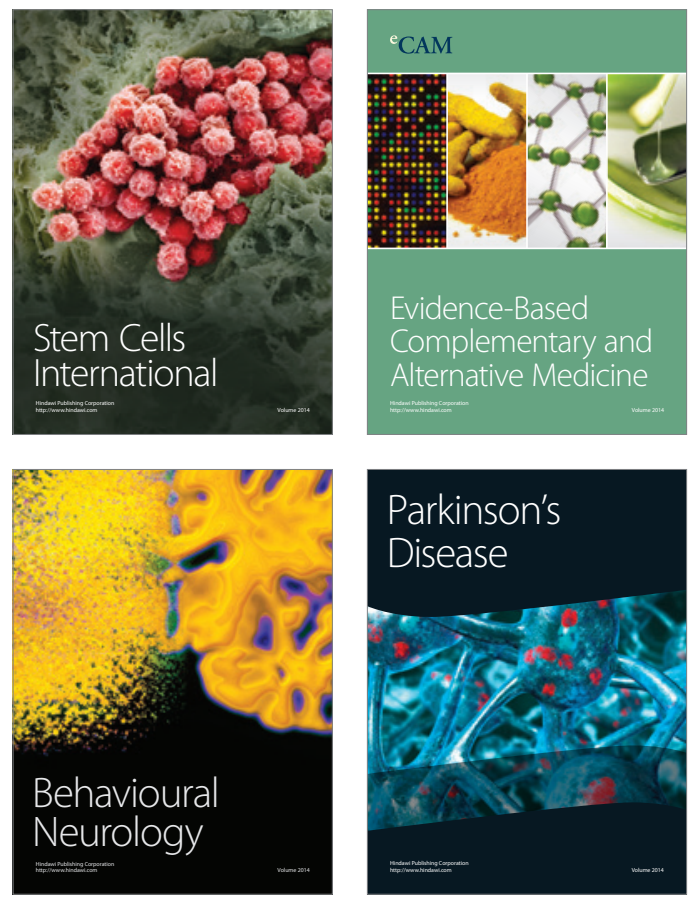
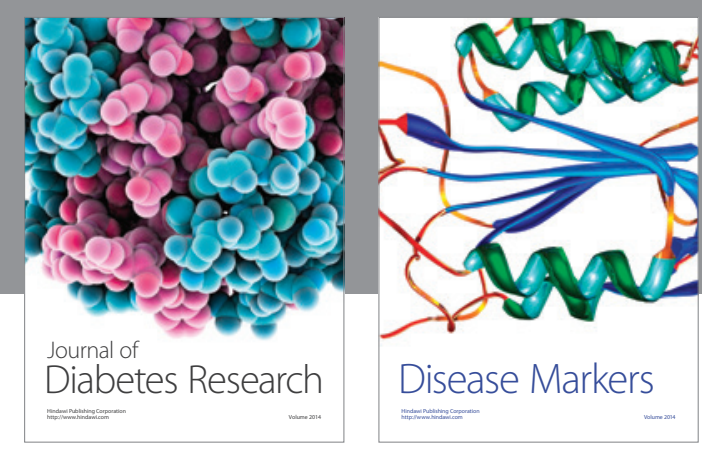

Disease Markers
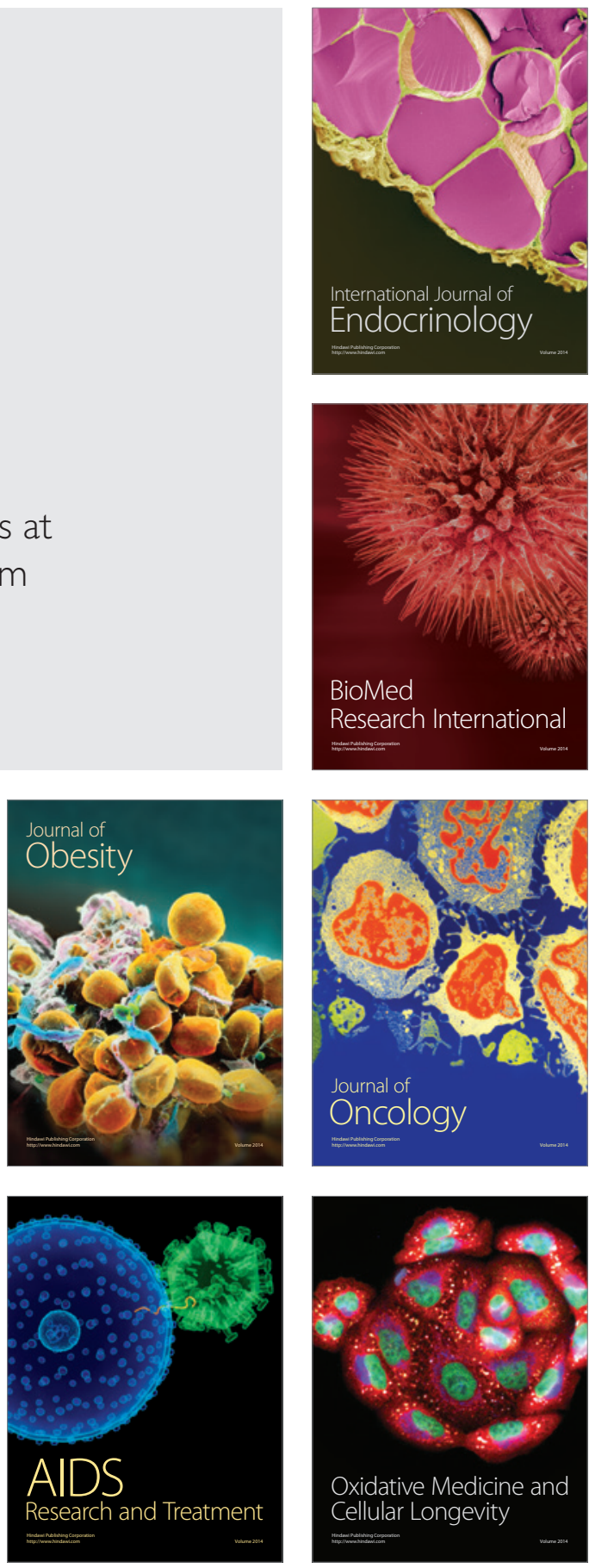